\title{
Ascending aorta cannulation in totally thoracoscopic minimally invasive cardiac surgery
}

Shengjie Liao ${ }^{1}$ and Xiaoshen Zhang ${ }^{1}$

${ }^{1}$ Affiliation not available

November 21, 2020

\begin{abstract}
The Cannulation through the femoral artery is the preferred method of establishing peripheral extracorporeal circulation in totally thoracoscopic minimally invasive cardiac surgery (MICS). However, facing to contraindications of femoral artery cannulation, a modified aortic cannulation is an alternative approach for totally thoracoscopic MICS.
\end{abstract}

\section{Hosted file}

Ascending aorta cannulation in MICS 1.pdf available at https://authorea.com/users/377641/ articles/494280-ascending-aorta-cannulation-in-totally-thoracoscopic-minimally-invasivecardiac-surgery

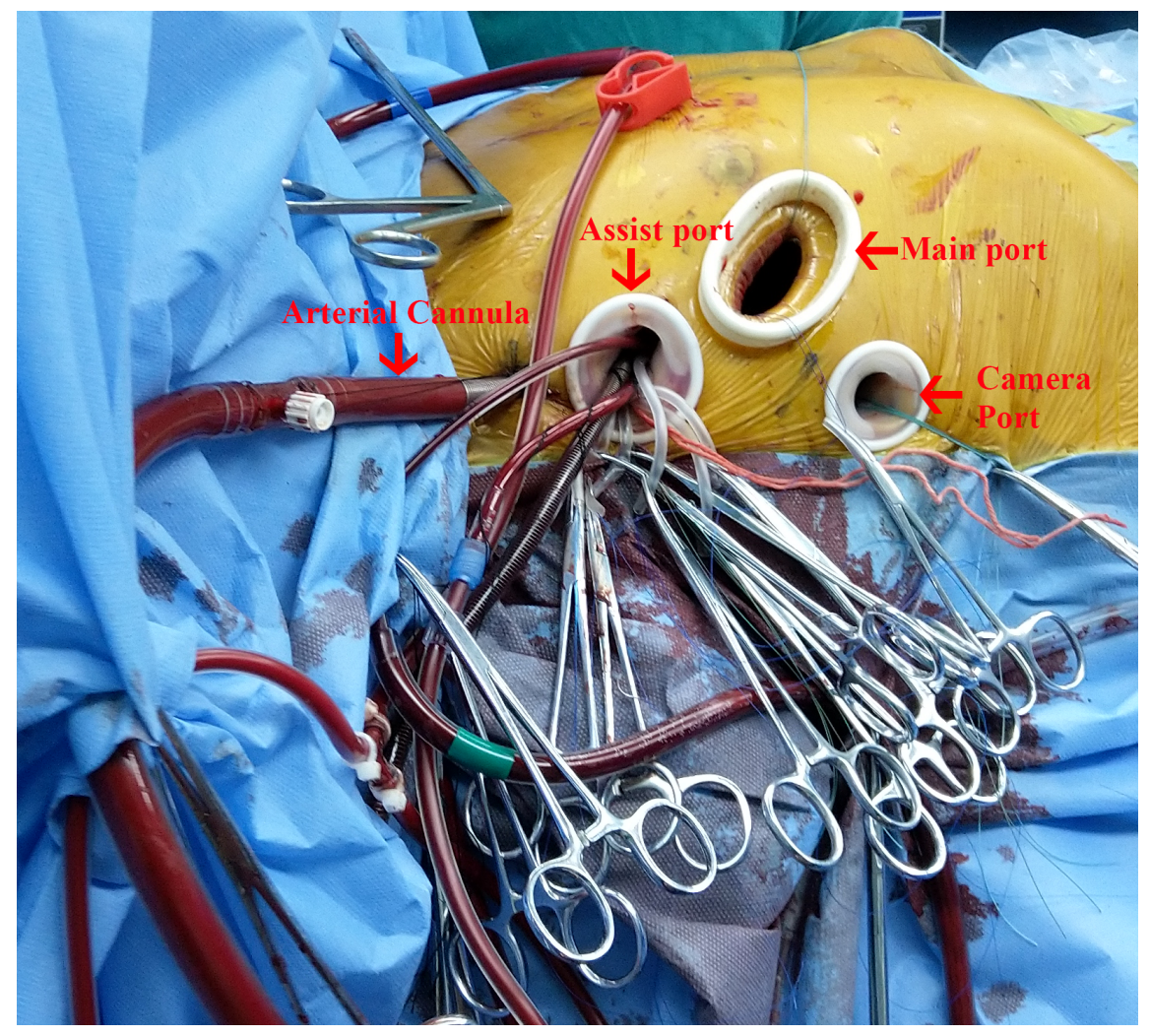




\section{Hosted file}

Ascending aorta cannulation in MICS.wmv available at https://authorea.com/users/377641/ articles/494280-ascending-aorta-cannulation-in-totally-thoracoscopic-minimally-invasivecardiac-surgery 